\title{
Princípios Pedagógicos dos Teaching Games for Understanding e da Pedagogia Não-Linear no Ensino da Educação Física
}

Filipe Manuel Clemente*

\begin{abstract}
Resumo: Os modelos de ensino ecológicos na Educação Física distingue-se pela sua pertinência no sentido de centrar o ensino no aluno. Especificamente, os Teaching Games for Understanding e a Pedagogia Não-Linear são modelos que possibilitam um processo pedagógico baseado na dinâmica intrínseca dos jogos desportivos, destacando-se pela sua pertinência para o desenvolvimento do conhecimento tático declarativo e processual dos alunos. No entanto, como modelos recentes necessitam de ser devidamente compreendidos e orientados no sentido de resultaram proficuamente na intervenção didática. Nesse sentido o presente artigo procura desenvolver os princípios pedagógicos que baseiam os modelos: i) a seleção do tipo de jogo; ii) a modificação do jogo por representação; iii) a modificação por exagero; e iv) o ajustamento da complexidade tática. Em suma, procurar-se-á definir os princípios basilares que deverão sustentar a intervenção didática do professor de Educação Física, aquando dos modelos ecológicos de ensino.
\end{abstract}

Palavras-Chave: Ensino. Educação Física. Ecologia.

\section{INTRODUÇÃO}

O ensino da Educação Física é um processo contínuo que depende intrinsecamente das novas teorias relacionadas com o processo de controlo e aprendizagem motora. Assim, acompanhando as teorias recentes que enfatizam a auto-organização dinâmica do processo de desempenho motor, novos modelos de ensino têm vindo a exaltar processos inovadores na forma de desenvolvimento dos alunos.

\footnotetext{
"Faculdade de Ciências do Desporto e Educação Física da Universidade de Coimbra, Coimbra, Portugal. E-mail: Filipe.clemente5@gmail.com
} 
De facto, o ensino tradicional baseado no professor onde as tarefas decompunham o jogo em diferentes fases, exaltando o processo analítico como garante da qualidade do ensino, tem vindo a ser cada vez mais discutido e debatido por novos modelos que centram o processo de ensino no aluno, enfatizando a necessidade de contextualizar a prática procurando exponenciar a participação do aluno na sua própria aprendizagem. Assim, modelos como os Teaching Games for Understanding (BUNKER; THORPE, 1986) e a Pedagogia Não-Linear (CHOW et al, 2006) são originadas no sentido de contrapor algumas tendências possivelmente nocivas à aprendizagem através de abordagens tradicionais de ensino, destacando: i) uma grande percentagem de jovens obtinha escasso sucesso como consequência da ênfase técnica; ii) os alunos ensinados através de modelos analíticos conheciam superficialmente o jogo e, por conseguinte, demonstravam fragilidade na forma de como abordar o mesmo; iii) os alunos com elevadas qualidades técnicas possuíam escassa capacidade de decisão em jogo e; iv) escassez de criatividade e reflexão sobre o desporto por parte dos agentes do mesmo (HOPPER, 2002; ARAÚJO, 2006).

Efetivamente, entenda-se que os modelos ecológicos que respeitam a integridade do jogo em cada momento da aprendizagem e em cada tarefa implementada são possíveis de serem desenvolvidos em qualquer modalidade ou prática desportiva. No entanto, tal fator é de relevância assinalável nos jogos desportivos de invasão onde a imprevisibilidade do jogo deve ser respeitada em qualquer momento, bem como, as suas características funcionais, pelo que, pretende-se com o presente artigo debater a estrutura dinâmica subjacente aos jogos desportivos de invasão, procurando definir os princípios didáticos do seu ensino atendendo aos modelos ecológicos enunciados anteriormente, i.e., Teaching Games for Understanding e Pedagogia Não-Linear. 


\section{Lógica INTERNA dos Jogos DesPoRtivos de INVASÃo}

A essência dos jogos desportivos relaciona-se com relações de oposição entre duas equipas coordenadas de forma a recuperar, conservar e movimentar a bola até alcançarem a zona de finalização e a respetiva concretização (GRÉHAIGNE; GODBOUT, 1995). Indo ao encontro do referido, Metzler (1987) descreve a essência dos jogos desportivos como a possibilidade de resolver em ação um conjunto inúmero e simultâneo de problemas imprevistos à partida de forma relativamente ordenada com o momento de surgimento, frequência e complexidade. Esta resolução de problemas acontece de forma simultânea na fase ofensiva e defensiva, dependendo do estado da equipa. No fundo, pretende-se enfatizar a natureza dinâmica e relacional dos jogos desportivos onde a complexidade referente a relações intra e inter-equipa perdura ao longo do tempo de jogo, adaptando-se coletivamente aos constrangimentos impostos pelo momento. Efetivamente, o jogo encerra em si uma relação de complexidade dependente da cooperação com os companheiros de equipas e da oposição com os adversários (GRÉHAIGNE; GODBOUT; BOUTHIER, 1999). Desta forma, a sistemática da observação dos jogos desportivos poderá contemplar duas grandes dimensões: i) o jogo, referente à relação de força entre equipas e; ii) a equipa, relacionado com a capacidade de relacionamento entre membros da equipa, i.e., o network (GRÉHAIGNE; GODBOUT, 1995; GRÉHAIGNE; BOUTHIER; DAVID, 1997; GRÉHAGINE; GODBOUT; BOUTHIER, 1999).

Face ao exposto, a dinâmica do jogo deve ser resolvida através de processos estratégicos e táticos no intuito de incrementar a proficiência interna da equipa de solucionar os constrangimentos impostos pelo adversário. A estratégia e a tática desde sempre apresentaram relevância em formas de oposição e cooperação da espécie humana (e.g., combates, guerra, jogos). No entanto, estratégia e a tática são dois termos distintos que devem ser devidamente interpretados no sentido de enfatizar a sua relevância 
no ponto de vista desportivo. Para Bouthier (1988), a estratégia refere-se a todos os planos, princípios de jogo, ou guias de ação que permitem definir a organização e preparação da equipa para o jogo. Por outro lado, a tática envolve a orientação de operações voluntárias e espontâneas executadas durante o jogo pelos jogadores no intuito de adaptar os requisitos iniciais aos eventos mutáveis do jogo relacionados com o dinamismo da equipa adversária, alterando, desta forma, alguns parâmetros relacionados com a estratégia definida.

Similarmente à descrição efetuada, Gréhaigne e Godbout (1995) descrevem a estratégia como os elementos antecipadamente discutidos para a organização da própria equipa. De facto, a estratégia relaciona-se com a ordem geral, i.e., o posicionamento dos membros da equipa, bem como, as zonas ocupadas e missões específicas de cada posição (GRÉHAIGNE, 1994; GRÉHAIGNE, GODBOUT; BOUTHIER, 1999). No que se refere à tática Gréhaigne e Godbout (1995) descrevem-na como uma adaptação pontual a novas configurações de jogo em função da circulação da bola e ações dos adversários. No fundo, a tática relaciona-se com o posicionamento em reação ao adversário numa determinada situação de jogo e com a adaptação da equipa às condições de jogo (GRÉHAIGNE, 1994).

Consequentemente, face ao exposto, existem diferenças substanciais entre estratégia e tática no que se refere ao tempo e ao espaço. Efetivamente, a estratégia associa-se com processos cognitivos mais elaborados do que propriamente com tomadas de decisão, devido ao seu maior tempo de realização e menor frequência de constrangimentos (GRÉHAIGNE; GODBOUT; BOUTHIER, 1999). De facto, a diferença substancial é que a tática se relaciona diretamente com constrangimentos espácio-temporais onde a tomada de decisão e a adaptação é substancialmente maior. Consequentemente, durante o jogo, especialmente para os jogadores próximos da bola, a tática é proeminente (GRÉHAIGNE; GODBOUT; BOUTHIER, 1999).

A tática é a inter-relação dos fatores do jogo: espaço, tempo, colega, bola, adversário, na dependência direta do objetivo final do desporto e dos objetivos táticos gerais e específicos da ação (BAYER, 
1986), pelo que, o conhecimento tático dos alunos é o conhecimento em ação, que possibilita ao praticante tomar decisões táticas em função do contexto (GARGANTA, 2006). A capacidade tática do praticante é constituída pela interação dos processos que desencadeiam tomadas de decisão, as quais objetivam a execução motora direcionada à obtenção da meta pretendida (MATIAS; GRECO, 2010). Assim, nas modalidades desportivas coletivas, a componente cognitiva centra-se nos processos de seleção de resposta e, desta forma, através da cognição, o praticante realiza a leitura de jogo (MATIAS; GRECO, 2010). Desta forma, importa enfatizar que a eficiência tática do aluno relaciona-se com a capacidade de decidir de forma célere em jogo, gerando um conjunto de respostas possíveis para responder a um dado problema (GRÉHAIGNE; GODBOUT; BOUTHIER, 1999).

Efetivamente a oposição, apesar de acarretar o incremento da complexidade para a ação dos jogadores, possibilita um conjunto de tomadas de decisão e reações que potenciam o desenvolvimento do praticante. De facto, as decisões dos alunos face à oposição devem ser tomadas considerando a continuidade/quebra referente a uma dada configuração de jogo atendendo ao estado de manutenção da posse de bola (GRÉHAIGNE; GODBOUT, 1995). Adicionalmente, segundo os autores, dois aspetos poderão ser fundamentais na gestão da ação por parte dos jogadores face à oposição: i) arriscar para ganhar vantagem ao adversário sustentado numa defesa coesa e; ii) optar pela estabilidade defensiva concedendo a iniciativa de jogo para os restantes jogadores. No fundo, a resolução de problemas de jogo basear-se-ão na capacidade reativa do jogador em interpretar o dinamismo de jogo e proceder à respetiva ação tendo como base a sua capacidade e conhecimento tático (CLEMENTE; MENDES, 2011).

Nas modalidades desportivas coletivas, os praticantes mais experientes possuem um conhecimento tático declarativo e processual superior aos praticantes com menor experiência, bem como um conhecimento mais estruturado e organizado que possibilita tomar decisões mais rápidas e exatas, verificando-se uma correlação 
positiva entre conhecimento e performance (MCPHERSON, 1994; MATIAS, et al., 2004; GRECO, 2006). Nos praticantes experientes, os níveis de conhecimento declarativo e processual apresentam uma maior proximidade enquanto que, nos praticantes de nível inferior, denota-se um desfasamento entre os dois conhecimentos para a performance (MATIAS; GRECO, 2010).

Perante o exposto, existem diferenças entre os praticantes experientes e inexperientes quanto à ação tática ressalvando-se, de entre outros, um maior conhecimento declarativo e processual; um conhecimento organizado e estruturado; uma maior objetividade nos processos de procura visual; uma melhor seleção dos sinais relevantes; uma maior capacidade de autorregulação tática ou; uma maior capacidade para planear as ações antecipadamente (WILliAMS, 2000; MANN, et al., 2007). No fundo, a aprendizagem dos alunos depende do contacto direto com fontes de informação pertinentes que lhes possibilitem a adequação funcional às características próprias de determinada modalidade praticada. Nesse sentido, o fornecimento de variabilidade ao processo de ensino afigura-se como benéfico no ponto de vista de conceder aos alunos experiências percetivas que lhes possibilitem aumentar as soluções de resolução de determinado problema vivenciado em jogo.

\section{Pedagogia Não-linear}

A pedagogia não-linear advém dos conceitos da psicologia ecológica e da teoria dos sistemas dinâmicos, podendo ser definida como a aplicação de conceitos e ferramentas não dinâmicas que suportam a prática docente (CHOW et al., 2006). Atendo à realidade complexa dos jogos coletivos de invasão, a natureza não-linear dos sistemas possibilitam a interação de componentes que, oscilando entre fases de estabilidade e instabilidade, constituem processos de autoorganização dependentes dos constrangimentos impostos (RENSHAW et al. , 2009). Para tal, o professor destaca-se pelo seu papel preponderante no momento de selecionar as tarefas e os constrangimentos impostos. De facto, segundo o modelo de pedagogia 
não-linear, uma das competências essenciais do professor reside na identificação e manipulação de constrangimentos essenciais que facilitem a emergência de ações funcionais e tomadas de decisão por parte dos alunos em diferentes modalidades ou práticas desportivas (CHOW et al., 2006). Consequentemente, tal facto prevê a constante interação entre o aluno e o meio, onde o âmago da prática didática deverá residir na facilitação de tarefas que promovam a aprendizagem dos alunos através da experimentação e consciencialização das diferentes ações em jogo, atendendo à ecologia da modalidade (RENSHAW et al., 2010). De facto, os alunos poderão afinar-se percetivamente com fontes essenciais de informação através da prática orientada pelo professor, estabelecendo um acoplamento informação-movimento guiando o comportamento do aluno (DAVIDS et al., 2001). No entanto, a profícua manipulação dos constrangimentos da tarefa por parte do professor de Educação Física requer o domínio de conhecimentos e experiência nos desportos, jogos e práticas desportivas abordadas (RENSHAW et al., 2010).

Efetivamente, sem o conhecimento robusto sobre determinada modalidade a eficácia do processo de ensino poderá ser comprometida, visto a manipulação de constrangimentos surtirem efeitos diferenciados em função dos objetivos estipulados. No fundo, para que exista sucesso na aplicação de constrangimentos da tarefa revela-se importante o professor conhecer os constrangimentos da tarefa que poderão exaltar a consecução de determinada ação por parte dos alunos (CLEMENTE et al., 2012). De facto, os professores encontram-se numa posição privilegiada para proceder a pequenas mas importantes alterações no ambiente de aprendizagem, conduzindo a alterações nos padrões de movimento e tomadas de decisão dos alunos (RENSHAW et al., 2010). Nesse sentido toda ação do professor deverá ser norteada por um planeamento sequenciado e esclarecido sobre os conteúdos e objetivos que pretende ver alcançados pelos alunos aquando da prática. Para tal, cada constrangimento ponderado deverá corresponder às necessidades intrínsecas do tipo de alunos e necessidades intrínsecas dos mesmos (CLEMENTE et al., 2012). De facto, a adoção da abordagem pedagógica não-linear, implica que os professores 
implementem uma variedade de constrangimentos que auxiliam os aprendizes a procuraram efetivas fontes de informação no sentido de adequar de forma eficaz a sua ação no contexto de prática (RENSHAW et al., 2010). Este processo deverá enfatizar a flexibilidade e adaptabilidade no sentido em que os alunos gerem movimentos únicos resolvendo problemas contextuais fruto do dinamismo complexo do jogo.

Atendendo à estrutura de prática importa salientar que, a prática, deverá objetivar a repetição sem repetição (BERNSTEIN, 1967). Efetivamente, inversamente à tradicional decomposição das tarefas, a pedagogia não-linear advoga a adoção da simplificação. Atendendo a Handford (2006), a comumente adotada decomposição das tarefas no que se refere à realidade ecológica do jogo, poderá desacoplar o processo informação-movimento reduzindo os efeitos didáticos no que concerne ao afinamento percetivo relativo à realidade do jogo. Ao invés, a simplificação das tarefas permite manter a integridade ecológica do jogo, mantendo os seus princípios em cada momento de aprendizagem. Assim, a prática procurará a repetição da exercitação mantendo a variabilidade da mesma, procurando tornar o processo de aprendizagem flexível e adaptável. No fundo, a exercitação imposta sob determinados constrangimentos permite aos alunos exercitarem de forma contínua os conteúdos definidos pelo professor e, simultaneamente, criarem novas soluções de resolução de problemas inerentes ao jogo devido à riqueza de acontecimentos provenientes da prática ecológica. Consequentemente, o ensino será repetição sem repetição, devido à variabilidade e fornecimento de autonomia de resolução de problemas aos alunos em prática. No entanto, a ecologia da tarefa não significa o jogo livre esperando que os alunos adquiram o conhecimento declarativo e processual. A ecologia da tarefa refere-se à exercitação imposta com constrangimentos definidos pelo professor que permitam aos alunos exercitarem de forma continuada determinado conteúdo tático, compreendendo a sua pertinência na realidade complexa do jogo (RENSHAW et al., 2010). Importa igualmente salientar que o planeamento das atividades não deverá basear-se na prescrição específica de soluções, mas sim no encorajamento do 
desenvolvimento de processos adaptativos por parte dos alunos possibilitando-lhes a descoberta das melhores situações em determinado momento e contextualização do jogo (BUTTON; CHOW; REIN, 2008).

\section{Princípios Pedagógicos dos Teaching Games for UNDERSTANDING}

Como analisado anteriormente as ideias fundamentais da pedagogia não-linear permitem fornecer novas perceções conceptuais no sentido de dotar os Teaching Games for Understanding como um modelo profícuo para o ensino da Educação Física (CHOW et al., 2007). Consequentemente, no sentido de potenciar a ação do professor na sua intervenção, quatro princípios pedagógicos baseiam a aplicação do modelo (GRIFFIN; BUTLER, 2005): i) a seleção do tipo de jogo; ii) a modificação do jogo por representação; iii) a modificação por exagero; e iv) o ajustamento da complexidade tática.

\subsection{SeleçÃo do Tipo de Jogo}

A seleção do tipo de jogo baseia-se no pressuposto que os jogos selecionados para a aprendizagem devem oferecer uma multiplicidade de experiências que possibilitem mostrar similaridades e diferenças entre jogos semelhantes e distintos, respetivamente (THORPE; BUNKER; ALMOND, 1984; THORPE; BUNKER, 1989). De facto, o sistema de classificação de jogos, permite reconhecer a similaridade e diferenciação entre diferentes modalidades, conferindo pertinência no momento de abordagem dos jogos. Hopper e Bell (2001) referem-se ao agrupamento dos jogos pela sua classificação enquanto semelhanças estruturais, sendo elas: i) jogos de alvo; ii) jogos de rede/parede; iii) jogos de batimento; e iv) jogos de invasão ou territoriais. Este sistema de agrupamento confere valor e facilidade no momento de integrar as tarefas na prática, conferindo a oportunidade de os alunos aprenderem conhecimentos táticos e estratégicos transversais a modalidades similares (THORPE; BUNKER; ALMOND, 1984; THORPE; BUNKER, 
1989). Assim, as componentes táticas e estratégicas relativas a cada grupo afiguram-se como um elemento fundamental para a aprendizagem transversal dos alunos, promovendo a transferibilidade das competências de reconhecimento de informações do jogo. Estes conteúdos táticos e estratégicos, quando apreendidos pelos alunos, poderão ser transferidos de um jogo para o outro, desde que em categorias similares, i.e., atendendo às especificidades das modalidades (TAN; CHOW; DAVIDS, 2011).

Consequentemente importa ao professor, no momento de definição dos conteúdos a abordar, percecionar a potencialidade da tarefa no sentido de promover aprendizagens passíveis de serem transferíveis para outra modalidade. Exemplificando um caso prático, a desmarcação é um dos conteúdos táticos de maior relevância nos jogos desportivos de invasão, pelo que, a sua aplicabilidade é transversal a diferentes desportos, tais como, futebol, andebol ou basquetebol. Assim, quando o professor promove tarefas constrangidas que visem potenciar a desmarcação deve procurar que esse mesmo conteúdo seja apreendido pelos alunos num ponto de vista transversal, realçando a sua aplicabilidade em diferentes momentos de jogos distintos. Desta forma, a seleção de tarefas de diferentes tipos de jogos poderão expor os alunos à variabilidade do formato dos jogos, auxiliando-os a percecionarem a realidade intrínseca de determinado grupo de modalidades, incrementando o seu conhecimento declarativo e processual sobre uma categoria de jogos (THORPE; BUNKER; ALMOND, 1984; THORPE; BUNKER, 1989).

Na pedagogia não-linear o princípio da seleção do tipo de jogo pode ser explicado pela relação entre as dinâmicas de distintas tarefas (a serem aprendidas) e a realidade dinâmica intrínseca aos alunos. Neste sentido o transfer positivo ocorre devido à dinâmica interna do aprendiz podendo suportar a sua aprendizagem e performance em jogos pertencentes à mesma categoria (TAN; CHOW; DAVIDS, 2011). No fundo, incumbe-se ao professor considerar, no momento do planeamento da tarefa, os objetivos e potencialidades dos alunos de compreenderem o objetivo em causa na tarefa. Quando essa 
apreensão de conhecimento acontece será possível ao aluno transferir a sua aprendizagem para jogos semelhantes. No caso, considerando o caso da desmarcação, ao percecionar a relevância da desmarcação em apoio ou rutura numa modalidade coletiva de invasão, o aluno encontrar-se preparado para considerar a sua aplicação numa modalidade semelhante, i.e., se no futebol o aluno compreende a dinâmica e pertinência da desmarcação em apoio e rutura, possivelmente encontrar-se-á afinado percetivamente para, no basquetebol, concretizar com sucesso a mesma ação em função de variáveis como o posicionamento da bola, dos companheiros e dos adversários.

Atendendo ao exposto, o princípio pedagógico da seleção do tipo de jogo revela-se como pertinente e profícuo no desenvolvimento do processo de ensino, expondo os alunos à prática de conteúdos táticos e estratégicos semelhantes em diferentes modalidades, facilitando a apreensão do conhecimento de forma transversal (TAN; CHOW; DAVIDS, 2011).

\subsection{ModificaÇÃo do Jogo POR REPRESENTAÇÃO}

A representação envolve o desenvolvimento modificado do jogo, através de jogos reduzidos que contêm a mesma estrutura tática dos jogos formais (e.g., Thorpe, Bunker \& Almond, 1984; Thorpe \& Bunker, 1989). O âmbito desta representatividade é facultar aos alunos oportunidades para desenvolverem de forma específica conteúdos táticos em situações que possibilitam tomadas de decisão adequadas em função das potencialidades dos praticantes (TAN; CHOW; DAVIDS, 2011).

Comummente, a literatura designa essas adaptações ao formato original dos jogos desportivos coletivos como jogos reduzidos (tradução do termo small-sided games). Assim, os jogos reduzidos são geralmente utilizados de forma a desenvolver aprendizagens ou parâmetros da performance de forma simultânea, enquadrando-os em tarefas ecológicas que emulem determinada situação ou especificidade de jogo (RAMPININI, et al., 2007; HILL-HAAS et al., 2009). 
A idealização e introdução de exercícios específicos dependem, invariavelmente, de fatores associados com o contexto da equipa e seus objetivos. Fatores como as capacidades condicionais dos praticantes, o momento do ano, os tempos de recuperação, os objetivos estratégicos e táticos, o nível técnicos dos praticantes ou o nível coletivo do grupo de praticantes deverão ser considerados, conjugadamente, no momento de conceção da tarefa (CLEMENTE et al., 2012). De facto, essa adequação e conjugação de fatores contextuais com os constrangimentos da tarefa poderão ser determinante para o sucesso e proficuidade da tarefa, enfatizandose a relevância dos jogos reduzidos para o desenvolvimento dos praticantes (HILL-HAAS et al., 2011). Realce-se que, não apenas fatores fisiológicos e técnico/táticos retiram proveito dos jogos reduzidos. Efetivamente, os jogos reduzidos promovem elevados níveis de prazer e dedicação entre os praticantes aumentando, simultaneamente, o nível de jogo dos mesmos ( WALL; CÔTÉ, 2007; SAMPAIO; ABRANTES; LEITE, 2009).

No entanto, atendendo ao fator pedagógico da representação do jogo, importa salientar a sua pertinência para a manutenção do acoplamento informação-movimento no que se refere à estrutura do jogo, mantendo a integridade ecológica da modalidade (TAN; CHOW; DAVIDS, 2011). O objetivo da representatividade encontrase em linha com a simplificação das tarefas, evitando a decomposição das mesmas no sentido de manter a integridade do jogo, i.e., salvaguardando os seus princípios constituintes táticos e dinâmicos intactos em cada tarefa (DAVIDS; BUTTON; BENNETT, 2008). Essencialmente, a representatividade da tarefa necessita de ser construída através de uma relação próxima entre a dinâmica da tarefa modificada e a dinâmica envolta no jogo formal (TAN; CHOW; DAVIDS, 2011). No fundo, cada tarefa necessitará de manter intacta a dinâmica inerente à modalidade, por exemplo, no caso do futebol, a relação cooperação-oposição deverá ser mantida no sentido de manter um dos princípios caracterizadores do jogo. 


\subsection{MODIFICAÇÃO POR EXAGERO}

Em cada tarefa simplificada e representativa do jogo, o professor deverá manter a preocupação de determinar um problema tático que emergirá a partir dos constrangimentos impostos à exercitação. Efetivamente, aquando da constituição da tarefa importa que os constrangimentos impostos guiem os alunos a compreender o dinamismo tático e estratégico resultante da prática. Num caso prático, uma tarefa de $2 \times 2$, poderá possuir como um dos constrangimentos os alunos pontuaram apenas através da receção do passe na linha de golo adversária. Tal constrangimento enfatizará a desmarcação em rutura por parte do jogador atacante sem bola. No fundo, esta tarefa, mantendo a integridade da cooperaçãooposição, regras e constituintes como a prática no plano longitudinal do campo, altera o objetivo da tarefa no sentido de exagerar a consecução da desmarcação em rutura procurando que os alunos apenas pontuem através da consecução do movimento.

Consequentemente os constrangimentos impostos deverão guiar os alunos a desempenharem as ações pretendidas, sendo que, o princípio do exagero mantém a integridade ecológica do jogo e, simultaneamente, procura concretizar a ação tática determinada previamente pelo professor. Assim, os constrangimentos da tarefa procuram enfatizar determinada fonte de informação, tornando óbvio para o aluno a consecução de determinada ação. Efetivamente, sem o exagero os alunos poderão manter-se menos afinados percetivamente com os parâmetros ecológicos essenciais que se revelam fundamentais para a tomada de decisão (TAN; CHOW; DAVIDS, 2011).

No entanto, nesta fase de aplicação da modificação por exagero importa que o professor conheça de forma inequívoca os fundamentos e dinamismo intrínseco do jogo no sentido de exponenciar a prática de determinado conteúdo tático. Sem um constrangimento adequado a consecução da ação será menos previsível e óbvia para os alunos. Adicionalmente, será importante confirmar a aprendizagem dos 
alunos, bem como, a sua compreensão sobre o problema tático presente no jogo. Para tal, importa que o professor recorra ao questionamento como forma de guiar os alunos à compreensão e resolução do problema inerente ao jogo.

Assim, segundo Light (2003), a capacidade de questionar os alunos, é um fator primordial que baseia o sucesso dos TGfU, conferindo-lhe um real valor pedagógico (PEARSON; WEBB; MCKEEN, 2005). No fundo a focagem do questionamento deverse-á centrar na capacidade de o aluno solucionar determinado problema tático enfatizado pelo professor, através de processos reflexivos internos (PEARSON; WEBB, 2008). Desta forma, os alunos são encorajados a analisarem a sua ação, individualmente ou coletivamente (PEARSON; WEBB, 2008). Consequentemente, o papel do professor dever-se-á centrar-se na capacidade de facilitar o processo de pensamento dos alunos, auxiliando-os e facultandolhes competências que lhes permitam interpretar e refletir sobre as ações inerentes ao jogo.

\subsection{Auustamento da Complexidade Tática}

O princípio pedagógico da complexidade tática envolve o desenvolvimento correspondente do jogo às competências e potencialidades dos alunos (TAN; CHOW; DAVIDS, 2011), i.e., o problema tático inerente à tarefa deve ser devidamente adequado ao nível de proficiência dos alunos. No fundo a complexidade da tarefa deve incrementar gradativamente em função do nível de experiência e compreensão dos alunos.

Efetivamente será de admitir que um dos constrangimentos a considerar no momento da prescrição das tarefas se relaciona com o número de praticantes, i.e., as formas de jogo. Em subfases de jogo inferiores (e.g., 2×2, 3×3) a variabilidade de ações será supostamente inferior comparativamente a formas de jogo com maior número de alunos, pelo que, as formas de jogo a considerar implicarão maior ou menor participação dos alunos, bem como, se relacionarão com a capacidade de os alunos percecionarem os conteúdos táticos 
em causa. Considerando esse exemplo, poder-se-á considerar os princípios táticos do futebol onde a sua estrutura tática deverá ser considerada no momento da evolução da complexidade pedagógica.

No caso prático do futebol, existem 5 princípios táticos fundamentais (GARGANTA; PINTO, 1994) e opostos para cada fase de jogo (i.e., ofensiva e defensiva), a saber: i) penetração/ contenção; ii) cobertura ofensiva/cobertura defensiva; iii) mobilidade/ equilíbrio; iv) espaço/concentração; e v) unidade ofensiva/unidade defensiva. Tais princípios táticos encontram-se diretamente relacionados com a evolução funcional da complexidade do jogo. No caso, enquanto que, a penetração/contenção se refere à díade atacante/defensor (i.e., 1x1), a cobertura ofensiva/cobertura defensiva corresponde à forma de jogo $2 \times 2$. Consequentemente, incumbe-se ao professor definir claramente o conteúdo tático a abordar sendo que, a complexidade do mesmo, dependerá do estado de conhecimento declarativo e processual dos alunos em relação ao objetivo.

Face ao exposto, importa enfatizar que os professores de Educação Física necessitam de ajustar a complexidade das tarefas de aprendizagem de forma apropriada e adequada possibilitando o desafio dos alunos e, simultaneamente, possibilitando o alcançar do sucesso interventivo (TAN; CHOW; DAVIDS, 2011). Todos os conteúdos deverão encontrar-se sequenciados de forma gradual atendendo à sua complexidade, possibilitando manter a ecologia da prática e, simultaneamente, a sua proficuidade para a aprendizagem dos constituintes do jogo.

\section{Conclusão}

O presente trabalho objetivou analisar os princípios pedagógicos que norteiam o processo de ensino dos modelos ecológicos em Educação Física. Efetivamente através do exposto importa salientar os novos desafios à prática docente onde o professor, necessita de se afigurar como um conhecedor intrínseco dos processos dinâmicos inerentes às diferentes modalidades e jogos desportivos. 
Efetivamente, apenas através de um conhecimento sustentado poderá desenvolver tarefas ecológicas que respeitem a realidade do jogo e, simultaneamente, despoletem nos praticantes os conteúdos que pretende ver desenvolvidos. Desta forma, a manipulação dos constrangimentos da tarefa revelam-se como fatores impreteríveis na consecução do processo didático (CLEMENTE; MENDES, 2011).

Assim, no que se refere ao processo de dinamização das tarefas, os princípios pedagógicos de seleção do tipo de jogo, modificação do jogo por representação, modificação por exagero e ajustamento da complexidade tática, revestem-se de importância para a concretização do sucesso e proficuidade educativa. Apenas através do comprimento destes princípios será possível nortear de forma correta o modelo de ensino não-linear, onde o jogo reduzido deverá ser devidamente guiado através de constrangimentos pertinentes que afinem percetivamente os alunos com os objetivos pretendidos pelo professor. De facto, a abordagem ecológica e prática não-linear em nada se assemelha com o jogo livre e não orientado. Pelo contrário, a definição de constrangimentos da tarefa que exultem os conteúdos táticos específicos e pretendidos pelo professor será uma das funções de maior complexidade na sua atuação didática, requisitando deste, um conhecimento profundo sobre os jogos, bem como, das formas de guiar os alunos à consecução dos objetivos pretendidos através da simplificação do jogo, no sentido de garantir a repetição sem repetição. 


\section{Pedagogical Principles of Teaching Games for Understanding and Nonlinear Pedagogy in the Physical Education Teaching}

Abstract: The ecological teaching models of Physical Education distinguished by their student-centered teaching. Specifically, the Teaching Games for Understanding and the Nonlinear Pedagogy are models that allow a learning process based on the intrinsic dynamics of sports games, distinguished for their relevance to the development of students' declarative and procedural tactical knowledge. However, as recent models, need to be properly understood and geared towards to the efficient didactic intervention. Therefore, the main objective of this paper is to develop the pedagogical principles that underlie the models: i) sampling; ii) representation; iii) exaggeration; and iv) tactical complexity. In summary, will described the essential pedagogical principles that should underpin the teaching intervention of physical education teacher at the time of applied the teaching ecological models. Keywords: Teaching. Physical Education. Ecology

\section{Principios Pedagógicos de la Enseñanza de Juegos para la Comprensión y la Pedagogía No Lineal en la enseñanza de la Educación Física}

Resumen: Los modelos ecológicos de la enseñanza en educación física se distinguen por su relevancia para la enseñanza centrada en el estudiante. En concreto, la Enseñanza de Juegos para la Comprensión y la pedagogía no lineal, son modelos que permiten un proceso de aprendizaje basado en la dinámica intrínseca de los juegos deportivos, especialmente por su relevancia para el desarrollo de conocimientos tácticos declarativo y procedimental de los estudiantes. Sin embargo, los modelos más recientes deben ser bien entendidos y dirigidos para dar lugar a efectos beneficiosos sobre el aprendizaje de los estudiantes. En consecuencia, este artículo tiene por objeto desarrollar los principios pedagógicos que subyacen en los modelos: i) seleccionar el tipo de juego; ii) la modificación del juego por representación; iii) la modificación por exageración; y iv) el ajuste de la complejidad táctica. En definitiva, se tratará de definir los principios básicos que deben sustentar la intervención de la enseñanza de profesor de educación física en el momento de desarrollo de los modelos ecológicos de enseñanza.

Palabras clave: enseñanza. Educación Física. Ecología 


\section{REFERÊNCIAS}

BAYER, C. La ensenanza de los juegos desportivos colectivos. Barcelona: Hispano Europea, 1986.

BERNSTEIN, N. A. The co-ordination and regulation of movements. Oxford: Pergamon Press, 1967.

BOUTHIER, D. Les conditions cognitive de la formation d'actions sportives collectives. Paris: Université Paris V, EPHE,1988.

BUNKER, D.; THORPE, R. From theory to practice. In: THORPE, R.; BUNKER, D.; ALMOND, L. (Eds.), Rethinking Games Teaching. Loughborough: University of Technology, 1986. p. 11-16.

BUTTON, C.; CHOW, J. Y.; REIN, R.. Exploring the perceptual-motor workspace: New approaches to skill acquisition and training. HONG, Y.; R. M. BARTLETT (Eds.), Routledge handbook of biomechanics and human movement science. London: Routledge, 2008.

CHOW, J. Y.; DAVIDS, K.; BUTTON, C.; SHUTTLEWORTH, R.; RENSHAW, I.; ARAÚJO, D. Nonlinear pedagogy: A constraints-led framework to understand emergence of game play and skills. Nonlinear Dynamics, Psychology and Life Sciences, Pewaukee, v. 10, n.1, 71-104, 2006.

CHOW, J. Y.; DAVIDS, K.; BUTTON, C.; SHUTTLEWORTH, R.; RENSHAW, I.;ARAÚJO, $D$. The role of nonlinear pedagogy in physical education. Review of Educational Research, Thousand Oaks, v. 77, n.3, p. 251-278, 2007.

CLEMENTE, F.; MENDES, R.. Aprender o jogo jogando: uma abordagem transdisciplinar. Revista Científica Exedra, Coimbra, v. 5, n.1, p. 27-36, 2011.

CLEMENTE, F.; COUCEIRO, M.; MARTINS, F.; MENDES, R. The usefulness of smallsided games on soccer training. Journal of Physical Education and Sport, Pite?ti, v. 12, n.1, p. 93-102,2012.

DAVIDS, K.; BUTTON, C.; BENNETT, S.. Dynamics of Skill Acquisition: A Constraints-Led Approach. Champaign: Human Kinetics, 2008.

DAVIDS, K.; WILLIAMS, M.; BUTTON, C.; COURT, M. An integrative modeling approach to the study of intentional and movement behavior. In. SINGLER, R.; HOUSENBLAS, H.; . JANELLE, C.. (Eds.), Handbook of sport psychology New York: John Wiley, 2001. p. 144-173.

GARGANTA, J. (Re) Fundar os conceitos de estratégia e táctica nos jogos desportivos colectivos, para promover uma eficácia superior. Revista Brasileira Educação Física e Esporte, São Paulo, v. 20, n.5, p. 201-103, 2006. 
GARGANTA, J.; PINTO, J.. O ensino do futebol. In: GRAÇA, A.; OLIVEIRA, J. (Eds.), $O$ ensino dos jogos desportivos Porto: Faculdade de Ciências do Desporto e de Educação Física da Universidade do Porto, 1994. p. 95-136.

GRECO, P.J.. Conhecimento tático-técnico: eixo pendular do comportamento e da ação nos esportes coletivos. Revista Brasileira Psicologia do Esporte e Exercício, Belo Horizonte, v.0, n.1, p. 107-129, 2006.

GRÉHAIGNE, J. F. Soccer: The players' action zone in a team. Second World Congress of Notational Analysis. Cardiff, England,1994.

GRÉHAIGNE, J. F.; BOUTHIER, D.; DAVID, B. Dynamic-system analysis of opponent relationship in collective actions in soccer. Journal of Sports Sciences, London, v.15, p. 137-149, 1997.

GRÉHAIGNE, J. F.; GODBOUT, P.. Tactical Knowledge in Team Sports from a Constructivist and Cognitivist Perspective. Quest, Champaign, v. 47, p. 490-505, 1995.

GRÉHAIGNE, J. F.; GODBOUT, P.; BOUTHIER, D. The Foundations of Tactics and Strategy in Team Sports. Journal of Teaching in Physical Education, Champaign, v. 18, p.159-174, 1999.

GRIFFIN, L.L.; BUTLER, J. Teaching games for understanding: theory, research, and practice. Champaigne, IL: Human Kinetics, 2005.

HANDFORD, C. H. Serving up variability and stability. In: DAVIDS, K.; BUTTON, C.; NEWELL, K (Eds.). Movement system variability. Champaign, IL: Human Kinetics, 2006.

HILL-HAAS, S. V.; DAWSON, B. T.; COUTTS, A. J.; ROWSELL, G. J. Physiological responses and time-motion characteristics of various small-sided soccer games in youth players. Journal of Sports Sciences, London, v. 27, n. 1, p. 1-8, 2009.

HILL-HAAS, S. V.; DAWSON, B.; IMPELLIZZERI, F. M.; COUTTS, A. J.. Physiology of Small-Sided Games Training in Football: A Systematic Review. Sports Medicine, Auckland, v. 41, n.3, p. 199-220, 2011.

HOPPER, T.; BELL, R.. Games classification system: Teaching strategic understanding and tactical awareness. The California Association for Health, Physical Education, Recreation and Dance, Sacramento, v. 66, n. 4, p.14-19, 2001.

LIGHT, R. The joy of learning: Emotion and learning in games through TGfU. Journal of Physical Education New Zealand, Canterbury, v. 36, n.1, p. 93-108, 2003.

MANN, D.Y.; WILLIAMS, A.; WARD, P.; JANELLE, C.M. Perceptual-cognitive expertise in sport: A meta-analysis. Journal of Sport Exercise Psychology, Champaign, v. 29, n.4, p. 457-478, 2007. 
MATIAS, C.J.; GIACOMINI, S.D.; GRECO, P.J. Conhecimento tático no voleibol: fator determinante ou não para se estar na seleção brasileira de voleibol. Revista Portuguesa de Ciências do Desporto, Porto, v. 4, n. 2, p. 490-490, 2004.

MATIAS, C.J.; GRECO, P.J. Cognição \& acção nos jogos esportivos colectivos. Ciências \& Cognição, Rio de Janeiro, v. 15, n.1, p. 252-271, 2010.

MCPHERSON, S.L. The development of sport expertise. Quest, Champaign, v.46, n.2, p. 223-240, 1994.

METZLER, J.. Fondements théoriques et pratiques d'une démarche d'enseignement des sports collectifes. Spirales, 1(Complément), p.143-151. 1987.

PEARSON, P.; WEBB, P. Developing effective questioning in Teaching Games for Understanding (TGfU). ASIA PACIFIC SPORT IN EDUCATION CONFERENCE, 1. Adelaide, 2008.

PEARSON, P.; WEBB, P.; MCKEEN, K. Teaching Games for Understanding (TGfU). $\mathbf{1 0}$ years in Australia Teaching Games for Understanding in the Asia Pacific Region. Hong Kong, 2005. p.1-9, 2005.

RAMPININI, E.; IMPELLIZZERI, F. M.; CASTAGNA, C.;ABT, G.; CHAMARI, K.; SASSI, A.; MARCORA, S. M.. Factors influencing physiological responses to small-sided soccer games. Journal of Sports Sciences, London, v. 25, n. 6, p. 659-666, 2007.

RENSHAW, I.; CHOW, J. Y.; DAVIDS,K.; HAMMOND, J.. A constraints-led perspective to understanding skill acquisition and game play: a basis for integration of motor learning theory and physical education praxis? Physical Education \& Sport Pedagogy, Abingdon, v.15, n.2, p. 117-137, 2010.

RENSHAW, I.; DAVIDS, K.; SHUTTLEWORTH, R.; CHOW, J.. Insights from ecological psychology and dynamical systems theory can underpin a philosophy of coaching. International Journal of Sport Psychology, Roma v. 40, p. 540-602, 2009.

SAMPAIO, J.; ABRANTES, C.; LEITE, N.. Power, heart rate and perceived exertion responses to $3 \times 3$ and $4 \times 4$ basketball small-sided games. Revista de Psicología del Deporte, Palma, v.18 (suppl), p. 463-467, 2009.

TAN, C. W. K.; CHOW, J. Y.; DAVIDS, K.. 'How does TGfU work?': examining the relationship between learning design in TGfU and a nonlinear pedagogy. Physical Education \& Sport Pedagogy, Abingdon, v.16, n. 4, 2011. DOI: 10.1080/ 17408989.2011.582486.

THORPE, R. D.; BUNKER, D. J.; ALMOND, L.. A change in focus for the teaching of games. In: PIERON, M.; GRAHAM, G. (Eds.), Sport pedagogy: Olympic Scientific Congress proceedings. Champaign, IL: Human Kinetics, 1984. p. 163-169).

THORPE, R.; BUNKER, D.. A changing focus in games teaching. In: ALMOND, L. (Ed.). The place of physical education in schools. London: Kogan Page, 1989. p. $42-71$. 
WALL, M.; CÔTE, J.. Developmental activities that lead to dropout and investment in sport. Physical Education and Sport Pedagogy, Abingdon, v. 12, n.1, p.77-87, 2007.

WILLIAMS, M.. Perceptual skill in team games: research, theory, and practice. Congrès International de la Société Française de Psychologie du Sport, v. 1, n.1, p. 1-2, 2009.

WILLIAMS, M.; WARD, P.; CHAPMAN, C. Training perceptual skill in field hockey: Is there transfer from the laboratory to the field? Research Quarterly for Exercise and Sport, Reston, v.74, n.11, p. 98-103, 2003.

Endereço para correspondência:

Faculdade de Ciências do Desporto e Educação Física

Universidade de Coimbra

Estádio Universitário, Pavilhão 3

Coimbra, Portugal

3040156

Recebido em: 20.04.2012

Aprovado em: 28.04.2012

Movimento, Porto Alegre, v. 18, n. 02, p. 315-335, abr/jun de 2012. 
